\title{
LA GLOBALIZACIÓN Y LAS REGIONES: UNA RELACIÓN INCIERTA
}

FERNANDO POZOS PONCE

Universidad de Guadalajara

Revista Geocalli, año 2, núm. 4, Universidad de Guadalajara, Guadalajara, 2001.

El título "Regiones y Globalización" que lleva el número cuatro de la revista Geocalli, me parece muy atinado pero a la vez polémico. Es atinado porque nos remite a una problemática o a una relación (global-regional) que es relevante analizar y estudiar en estos días, dado el impacto que tiene el proceso de globalización en las regiones. Pero también es un título polémico, porque hay un conjunto de instituciones y actores económicos y políticos que argumentan que la globalización es un proceso ineludible, contundente y progresivo, ante el cual las regiones y quienes en ellas habitan no tienen otra alternativa que asumir sus consecuencias y sumarse a su dinámica. Pero afortunadamente también hay un grupo importante de instituciones y actores que proponen un diálogo, una negociación entre los factores globales y las especificidades regionales, de tal suerte que ni la globalización es determinante para las regiones, ni las regiones son entes absolutamente abiertos y dispuestos a ser transformados por los caprichosos factores de la globalización. Mucho se ha escrito sobre esta polémica y creo que seguiremos encontrando propuestas y análisis sobre esta relación necesaria, pero bidireccional, entre lo global y lo regional.

En este debate se inscriben, desde mi punto de vista, los dos exten- 
sos artículos que componen el número cuatro de la revista Geocalli. El primero de ellos, escrito por J. Rentería y titulado "Una aproximación teórica y práctica al concepto de región", aborda uno de los problemas más viejos del análisis regional: ¿Qué es una región? El autor intenta integrar una serie de elementos para que contribuyan al análisis de la Región Occidente de México. En su artículo, Rentería intenta identificar los elementos teóricos que son esenciales para definir lo que es una región. Después de revisar las primeras conceptualizaciones de región, tales como la región natural (donde predominan las características del medio ambiente), la región socioeconómica (donde lo central son las actividades productivas y relaciones económicas entre los pobladores) y la región vista como el acervo tecnológico de una sociedad manifiesta en el espacio, el autor concluye proponiendo una integración de todos los elementos anteriores para definir una región:

ésta se configura a través de una relación recíproca y simultánea entre dos polos; la naturaleza de su estructura aparece en una acción combinada entre los rasgos y propiedades múltiples que la conforman ¿Cómo reconocer un límite regional, sin a la vez conocer la combinación particular de las condiciones naturales y los mecanismos de apropiación, a través del trabajo de la sociedad?

Ahora bien, para analizar una región, considerando tanto los elementos naturales como los sociales y tecnológicos, es necesario adoptar un enfoque multidisciplinario, donde cada perspectiva disciplinar rescate la importancia que tienen los elementos o factores propios y los convierta en variables explicativas del fenómeno o de la problemática que se desea estudiar en el espacio denominado región.

En este sentido, el autor pone en cuestión las perspectivas que afirman que es necesario identificar en un espacio la homogeneidad de sus características, la funcionalidad de varios procesos, la centralidad de un factor o el diseño administrativo, todo ello para definir un territorio como región. La complejidad de este ejercicio analítico ha generado propuestas de otros autores que se han enfrentado a la tarea de definir un espacio como región, considerando varios factores. Algunos de estos académicos, como José Luis Coraggio, enfatizan que la región es el resultado de un proceso amplio, donde el ser humano transforma el espacio y le imprime sus especificidades culturales; otro es Bryan Roberts, quien se- 
ñala que es necesario tomar en cuenta todos los factores que caracterizan a una región y convertirlos en una construcción heurística, abstracta, pero que resulte útil analíticamente. Un autor más, Eric Van Young, tiene un texto que nos brinda una serie de reflexiones sobre la importancia de las regiones como instrumentos analíticos para identificar procesos o fenómenos que se llevan a cabo en un espacio determinado, sin olvidar la complejidad que reviste el estudio y la definición de una región; a tal grado que en un momento afirma: las regiones son tan evidentes, que todo mundo las identifica. ${ }^{1}$

El autor termina su artículo señalando la necesidad de estudiar a la región Occidente de México dejando de lado concepciones rígidas y delimitaciones territoriales convencionales y dirigiendo el esfuerzo a identificar problemas, fenómenos y proce-

1 Ver: J. J. Coraggio et al., Experiencias de planificación regional en América Latina. Una teoría en busca de una práctica, Santiago, ILPES-CEPAL, 1981; Eric Van Young, "Are Regions Good to Think?", en E. Van Young (ed.), en Mexico's Regions, San Diego, Center for U.S. Mexican Studies, 1992; Brian Roberts, "Estado y Región en América Latina", en Relaciones, Vol. I, No. 4, 1980, pp. 9-40. sos, y sean ellos los que nos conduzcan a definir a la región.

El segundo artículo titulado "México y sus regiones. El contexto espacial de la globalización" de J. Delgadillo, F. Torres y J. Gasca, se inscribe también en la discusión sobre la relación entre lo global y lo regional, pero antes de tomar una posición al respecto, los autores hacen un recuento del desarrollo regional en México, de las principales tendencias y actores que han participado en él. Los autores señalan algunos casos en los que el Estado aparece como promotor del desarrollo regional a través de programas que no consideraban las variables propias de una política de desarrollo regional. En gran medida, afirman los autores, el saldo de este proceso fue el desequilibrio en el desarrollo regional a lo largo del territorio nacional. Se identifican los principales factores del fracaso en la integración regional: desarticulación entre la política regional y la política económica, fuerte centralización, libre mercado que genera desequilibrios territoriales, nueva política de regionalización que no atiende las desigualdades regionales, desarrollo regional que se dinamiza desde fuera, marginación social convertida en expresión del desequilibrio 
regional, desarrollo regional enfrentado a un problema de concepción y diseño para asumir los nuevos retos, procesos de descentralización que carecen de un plan articulador que atienda las ventajas regionales, falta de conciliación entre el modelo económico exportador y los desequilibrios económicos y sociales regionales.

Todo esto lleva a los autores a afirmar que el desarrollo regional tiene un futuro poco promisorio ante el embate globalizador. El Estado es un actor esencial que, sin embargo, ha cedido grandes espacios en el ámbito del desarrollo regional, a pesar de lo cual está presente y actuante en otros procesos, como la apertura de las fronteras. Los autores señalan que el Estado puede constituirse en un actor decisivo y relevante si aprovecha su capacidad para distribuir u orientar las inversiones que llegan a ciertas regiones del país, de tal forma que no sólo sean los actores regionales, sobre todo los que cuentan con más ventajas en infraestructura, los que den cauce a las inversiones extranjeras.

Los autores identifican dos dinámicas en proceso globalizador en el que está inserto el país: 1) La existencia de zonas productivas, mercados jerarquizados y articulados de acuerdo a la funcionalidad de cada parte en una cadena general de interdependencias; y 2) La globalización, en términos de la división internacional del trabajo, no abarca países en su conjunto sino espacios subnacionales, regiones, ciudades y localidades que podrían pasar a representar los nuevos ejes articuladores de la economía mundial. Esto cuestiona directamente la existencia o proceso de conformación de las regiones y de los subsistemas de ciudades existentes. Es decir, se espera un proceso de transformaciones diversas en diferentes áreas del territorio nacional, que pueden ser de integración o de fragmentación territorial. En este escenario es donde adquieren una gran importancia los nuevos actores del desarrollo regional, que son, según los autores, los empresarios y sus estrategias para enfrentar a la dinámica del capital global y definir las formas, los ritmos de crecimiento y la articulación de los territorios.

Este escenario exige una evaluación seria de cada una de las regiones del país, con el fin de diseñar estrategias específicas para cada territorio y para potenciar o desarrollar ventajas comparativas que permitan a las regiones ser competitivas y buscar formas de aprovechar los flujos

182 C C A 
de capitales o los mercados internacionales. En este sentido, los autores hacen un llamado de alerta al Estado y a los actores que pueden tener una mayor incidencia en estos procesos productivos y económicos, para no sólo brindar paliativos a las poblaciones de las regiones que siguen sumidas en el atraso y la marginación, sino para diseñar una estrategia que considere factores estructurales globales (productivos, mercados, tecnología), sin olvidar especificidades regionales y locales como recursos naturales (con una perspectiva de sustentabilidad), infraestructura, localización geográfica, acervos culturales y tecnológicos y capacidades laborales de la población, por mencionar algunos.

Utilizando diversos indicadores socioeconómicos, los autores caracterizan a las regiones y a subsistemas de ciudades para mostrar cuáles regiones cuentan con mayores ventajas para incorporarse a la dinámica de la economía global y cuáles se encuentran en una situación de rezago y marginación. Con este mismo conjunto de indicadores, los autores logran identificar algunas ciudades que se han convertido en puntos nodales de este nuevo proceso productivo y económico en que se encuentra inmerso el país desde hace por lo menos dos décadas.

El texto concluye señalando una serie de acciones y tareas por realizar para aprovechar de manera más incluyente las consecuencias de la dinámica propia del proceso globalizador, en lo que se refiere a producción industrial, desarrollo urbano e integración regional y social.

Ahora bien, quisiera señalar tres cuestiones que, desde mi punto de vista, no han sido abordadas de manera explícita por ninguno de los artículos que componen este número de Geocalli.

La primera se refiere a que estamos contrastando dos procesos: por un lado, la globalización, que es fenómeno bastante reciente y sobre cuya naturaleza y posibles consecuencias todavía no hay consensos; por el otro, está el desarrollo regional, fenómeno de más edad y sobre el que se ha discutido y escrito bastante, lográndose llegar a ciertos puntos de acuerdo que constituyen perspectivas analíticas útiles, aunque perfectibles, para analizar diversos fenómenos que se llevan a cabo en un espacio determinado. En este sentido, es necesario tomar con reservas el concepto de globalización.

En segundo lugar es necesario ser cautelosos cuando estudiamos la 
globalización, porque es un fenómeno que se caracteriza por una alta volatilidad; es decir, es un proceso que se manifiesta de diversas maneras y en periodos relativamente cortos. Si echamos marcha atrás en el tiempo, podemos afirmar que en los últimos 20 años la economía de México, de América Latina y del mundo han experimentado crisis económicas recurrentes, con efectos diferenciados en cada país o bloque de países. Hoy mismo, estamos en el umbral de una crisis económica que puede tener una escala global. Globalización, entonces, no significa necesariamente estabilidad y crecimiento económico sostenido.

Finalmente, otra característica de la globalización es la poca garantía de generar procesos de inclusión social y económica como resultado de una mayor integración de un país, región o ciudad a la dinámica global. Pongamos un ejemplo de varios que hay en el país. Hace cinco años, las autoridades del estado de Jalisco hicieron serios esfuerzos para integrar la Zona Metropolitana de la ciudad de Guadalajara a los circuitos de la producción industrial, sobre todo a la industria electrónica y de comunicaciones. En esos años se construyó infraestructura, se instalaron empresas y se generaron empleos; pero esto no redundó en un proceso de desarrollo y capacitación de la mano de obra involucrada en esas industrias, sus remuneraciones oscilaban entre uno y dos salarios mínimos, sus empleos eran rutinarios y con pocas posibilidades de desarrollo de una carrera laboral. En lo que se refiere a las empresas locales, éstas tuvieron serios problemas para integrarse como proveedores a las industrias que llegaron del extranjero, de tal forma que no se observó un proceso de encadenamiento productivo que beneficiara a la planta productiva local. En definitiva, a mayor apertura de una región al proceso globalizador no corresponde forzosamente un mayor grado de desarrollo social, laboral y productivo para dicha región. 